\title{
Factors influencing the acceptance and awareness of permanent method of family planning
}

\author{
Nishita Shettian*, Disha Ajila
}

Department of Obstetrics and Gynecology, A. J. Institute of Medical Sciences, Mangalore, Karnataka, India

Received: 29 January 2018

Accepted: 03 February 2018

\section{*Correspondence:}

Dr. Nishita Shettian,

E-mail: drnishitafernandes@yahoo.com

Copyright: (C) the author(s), publisher and licensee Medip Academy. This is an open-access article distributed under the terms of the Creative Commons Attribution Non-Commercial License, which permits unrestricted non-commercial use, distribution, and reproduction in any medium, provided the original work is properly cited.

\begin{abstract}
Background: Among developing countries, India holds the second place in being the most populated country accounting to 1.3 billion. This addresses the need for effective population control by implementing various family planning and contraceptive services thereby improving the quality of life. Our study aims at assessing the factors influencing the awareness and acceptance of permanent method of family planning.

Methods: This is a questionnaire based cross sectional study carried out in A.J. institute of Medical Sciences on 300 postpartum women who have undergone two or more child births.

Results: $77.3 \%$ of women were aware of family planning services out of which $64.3 \%$ had knowledge about permanent method of sterilization. $73 \%$ preferred to undergo tubectomy whereas only $13.7 \%$ were willing for vasectomy with the main reason for refusal being fear of surgery (25.9\%). 32.6\% of women wanted their husbands to undergo vasectomy rather than having a tubectomy themselves. Desire for more children (39\%) was the main reason given by most women who refused to undergo tubectomy.

Conclusions: Though women were aware of contraceptive practices, proper knowledge about permanent methods of family planning was still inadequate especially regarding vasectomy. Our study showed that lack of awareness and knowledge, fear of adverse effects, fear of sexual dysfunction, culture and religious beliefs, opposition from the male partner and health concerns were the factors influencing tubectomy acceptance over vasectomy as a permanent method of sterilization.
\end{abstract}

Keywords: Family planning, Permanent sterilization, Tubectomy, Vasectomy

\section{INTRODUCTION}

Being one of the developing countries, India currently holds the second place in being the most populated country in the world accounting to 1.3 billion. Half of our Indian population are believed to be of the reproductive age group thereby contributing to the existing population explosion. ${ }^{1}$ National development today is hindered by one of the major factors that is uncontrolled population growth despite India being the first country in the world to put an effort to initiate a national population control programme. ${ }^{2}$ This issue warrants immediate measures for effective population control by implementing various family planning and contraceptive services thereby hoping to improve the quality of life. ${ }^{3}$

Among the various methods of contraception available today, permanent method of sterilization is now gaining popularity worldwide especially in the developing countries facing population boom. It is an excellent choice of contraception for millions of men and women especially those who have completed their families and are on the lookout for a permanent solution to fertility control. These men and women must have clearly understood it's permanence and often unsuccessful reversal. ${ }^{4}$ However, it has to be taken into consideration 
that all women must be counselled about the alternative methods of contraception as well and allowed to take a decision themselves.

The approach for permanent method of family planning in women was tubectomy or tubal ligation. This was done either by mini laparotomy or by laparoscopic sterilization techniques. Among men, vasectomy or ligation of the vas deferens was the mode of permanent sterilization. ${ }^{3,5}$ Present study aims at assessing the factors influencing the awareness and acceptance of permanent method of family planning.

\section{METHODS}

This is a questionnaire based cross sectional study carried out in A.J. Institute of Medical Sciences. A sample size of 300 postnatal women admitted to the postnatal ward of our hospital were included in the study. The women recruited for participating in the study were the ones who have undergone two or more childbirths irrespective of the mode of delivery.

After obtaining consent from these postnatal mothers they were briefed regarding the study and a detailed predesigned structured questionnaire was handed out to these women. The questionnaire consisted of a total of 15 questions which would assess their knowledge, awareness and acceptance of permanent methods of sterilization namely tubectomy and vasectomy. They were then asked to tick the most appropriate answer according to them. They were free to ask questions or clear doubts if any. They had the right to withdraw from participating in the study at any point of time. A translator was provided for those who did not follow English. Anonymity and confidentiality of the participant was ensured at all times. The questionnaires were then collected and statistical analysis of the data was done.

\section{Inclusion criteria}

Postpartum women who have undergone two or more childbirths admitted in the postnatal ward.

\section{Exclusion criteria}

Primiparous women and those who did not consent to participate.

\section{Statistical analysis}

Statistical analysis was done using Chi square test and a P value of $<0.05$ was considered statistically significant.

\section{RESULTS}

Women who were aware of family planning services in our study accounted to $77.3 \%$ out of which $64.3 \%$ had knowledge about permanent method of sterilization. The main source of knowledge about tubectomy and vasectomy was found to be from health care professionals mainly doctors and nurses.

$48.7 \%$ of women felt that permanent method of sterilization is the best method of contraception for those who have completed their family. However, $49.3 \%$ of women had no idea that even men could undergo permanent method of sterilization. $76 \%$ of women were not aware of the fact that permanent method of family planning could also have failure rates. $30.3 \%$ of women knew that tubal ligation could be reversed by recanalization procedure if required, though they weren't aware of the success rates associated with the procedure.

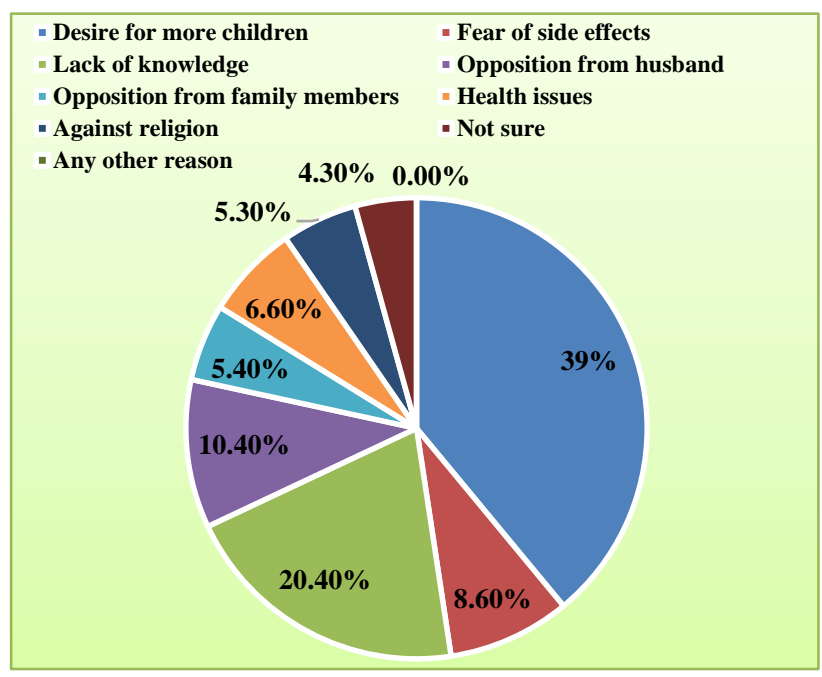

Figure 1: Reasons for women refusing to undergo tubectomy.

Out of the women who had completed their families $73 \%$ preferred to undergo tubectomy. Among those who refused the procedure of tubal ligation the main reason was found to be desire for more children (39\%) followed by lack of knowledge (20.4\%) (Figure 1).

When questioned about the number of children they expected to have $56.27 \%$ said 2 children, $25 \%$ wanted 3, $5.6 \%$ preferred to have 4 and $1 \%$ wanted to have more than 4 children. $4.3 \%$ of women weren't sure about how many children they would have since they hadn't decided nor discussed about it with their partners and $7.6 \%$ did not give an answer.

$32.6 \%$ of women wanted their husbands to undergo vasectomy rather than having a tubectomy themselves but only $13.7 \%$ were confident that their partners or husbands were willing for vasectomy.

The main reason for refusal of vasectomy was fear of surgery $(25.9 \%)$. The other reasons were found to be lack of knowledge, false belief that sterilization procedures are only meant for women, opposition from family members, fear of side effects and desire for more children (Figure 2). This highlighted the fact that husbands play a major 
role in decision making especially concerning family planning methods.

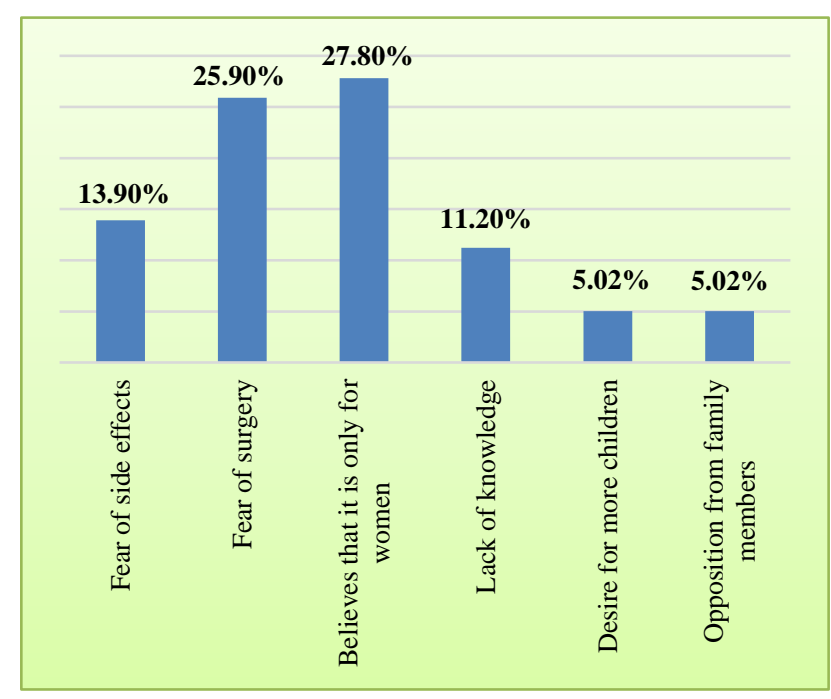

Figure 2: Factors affecting acceptance of vasectomy.

\section{DISCUSSION}

Awareness of family planning services among women in this study was a bit low (77.3\%) compared to studies done by Lakshmi et al where $94.5 \%$ were aware of family planning services, Anjum et al $93.6 \%$, Srivastav et al and Khan et al 81\%. ${ }^{2,3,6,7}$ Nair et al, Deka et al and Bhargava et al found that the knowledge was $80 \% \cdot{ }^{8-10}$ However, the awareness in our study was higher than the study done by Malik et al where only $68.4 \%$ were aware of contraceptive methods. ${ }^{11}$

It was found that $64.3 \%$ of our women had knowledge about permanent methods of sterilization which was comparable to a study done by Lakshmi et al in Tirupati where $58 \%$ had knowledge. ${ }^{3}$ A similar study done by Srivastav et al found that half of the women $(51.71 \%)$ recruited in their study knew about tubectomy and vasectomy. $^{2}$ Awareness about permanent method of sterilization was quite low in studies done by Malik et al in Pakistan (26.4\%), Mekonnen et al in Ethiopia (18\%) and Renjhen et al among students of Government medical college in Sikkim where only $12 \%$ were aware. ${ }^{11-13}$

The main source of knowledge about permanent method of sterilization in our study was found to be from health care professionals mainly doctors and nurses as stated in similar studies in comparison with other studies where knowledge was updated mainly through newspapers and mass media. ${ }^{1,2,6,8-10}$

According to Lakshmi et al most women preferred to undergo permanent sterilization procedure after having 2 to 3 children $^{3}$ whereas in our study $5.6 \%$ of women wanted to have 4 children and $1 \%$ even expressed her desire to have more than 4. Most of the women in a study done by Malik et al in Pakistan had parity more than $5 .{ }^{11}$
This issue addresses the deficiency in educating women on the need for effective family planning methods especially permanent method of sterilization for those who have completed their families or after 2 to 3 children.

$94 \%$ of women who have completed their families preferred to undergo tubectomy according to the study by Lakshmi et al, the main reason being ease of surgery, lack of knowledge about vasectomy procedure and financial constraints ${ }^{3}$ whereas only $73 \%$ of women in present study preferred the same due to poor decision-making power as most of the decisions were made by the husband.

Among those who refused to undergo tubal ligation 39\% of women in our study expressed desire for more children as was the reason stated in a similar study conducted by Nair et al where $48.8 \%$ refused tubectomy as they preferred to have more children. ${ }^{8} 20.4 \%$ of our women lacked knowledge about tubectomy procedure which invites the need for family planning and education programmes. Following health education, it was reported that the knowledge was improved to $100 \%$ as per the study by Anjum et al among married women in Jabalpur city. ${ }^{6}$

$32.6 \%$ of the women in present study wanted their husbands to undergo vasectomy instead of undergoing a tubectomy themselves. A study done by Lakshmi et al revealed that $69 \%$ of women did not want vasectomy for their husbands and $52.5 \%$ of the husbands were not willing for vasectomy. ${ }^{3}$ It was observed that the most common reason for refusal of vasectomy in most studies including ours was found to be fear of surgery. ${ }^{2,9-11}$ Therefore, it is a matter of concern which requires immediate attention for updating the knowledge of both men and women regarding strategies for national development and population control.

\section{CONCLUSION}

Though women were aware of most of the existing contraceptive practices, our study showed that there was lack of awareness and proper knowledge about permanent methods of family planning. Information and understanding about vasectomy procedure was still inadequate.Apprehension regarding adverse effects, fear of sexual dysfunction, culture and religious beliefs, opposition from the male partner and health concerns were the factors influencing tubectomy acceptance over vasectomy as a permanent method of sterilization. There is a strong need for organising medical education programmes to motivate more women as well as men to accept permanent method of sterilization in order to achieve the desired goals.

\section{Funding: No funding sources \\ Conflict of interest: None declared \\ Ethical approval: Not required}




\section{REFERENCES}

1. Nayak AU, Ramakrishnan KG, Venkateswar KN, Vijayshree M. Assessing the knowledge, attitude and practice of contraception in rural India: a necessary step in achieving population control. Int $\mathbf{J}$ Reprod Contracept Obstet Gynecol. 2017;6:3328-31.

2. Srivastav A, Khan MS, Chauhan CR. Knowledge, attitude and practices about contraceptive among married reproductive females. Int J Sci Study. 2014;1(5):2-4.

3. Lakshmi SG, Chandrasekhran PA, Radharani G. A study on factors influencing the choice of permanent method of family planning. IOSR-JDMS. 2015;14:16-22.

4. Cunningham GF, Leveno KJ. Section 6. Sterilization. William's obstetrics. $23^{\text {rd }}$ ed. New York7 McGraw-Hill. 2010:698-704

5. Chaudhuri SK. Practice of Fertility Control. $7^{\text {th }}$ ed. Elsevier;2008:178-226.

6. Anjum S, Durgawale PM, Shinde M. Knowledge of contraceptives methods and appraisal of health education among married woman. Int J Sci Res. 2014;3(3):584-90.

7. Khan A, Hashmi HA, Naqvi Z. Awareness and practice of contraception among child bearing age women. J Surg Pak. 2011;16(4):179-82.

8. Nair A, Devi S. Knowledge and attitude of puerperal women towards family planning practices in a tertiary care hospital. J Evid Based Med Healthc. 2017;4(5):212-6.
9. Deka N, Sarma AK, Borthakur S. Awareness and knowledge of contraception among parous women and contraceptive usage by them. Int $\mathrm{J}$ Health Res Med Legal Prac. 2017; 3:27-9.

10. Bhargava S, Hooja N, Nawal R, Kumawat B, Sharma A, Manish R. Knowledge and behaviour regarding birth prevention of healthcare providers. J Obstet Gynecol Ind. 2017;67:282-5.

11. Malik ZI, Habib SA, Rehman MZ, Maqbool A. Contraceptive knowledge, attitude and practice among parous women attending gynae outdoor of Shaikh Zayed Hospital, Rahim Yar Khan. Pak J Med Health Sci. 2015 Jan;9(1):80-3.

12. Getachew M, Enquselassie F, Gezahegn $T$, Agumasie S. prevalence and factors affecting use of long acting and permanent contraceptive methods in Jinka Town, Southern Ethiopia: a cross sectional study. Pan Afr Med J. 2014;18:98.

13. Renjhen P, Kumar A, Pattanshetty S, Sagir A, Samarasinghe CM. A study on knowledge, attitude and practice of contraception among college students in Sikkim, India. J Turkish German Gynecol Assoc. 2010;11:78-81.

Cite this article as: Shettian N, Ajila D. Factors influencing the acceptance and awareness of permanent method of family planning. Int J Reprod Contracept Obstet Gynecol 2018;7:875-8. 